\title{
Coerência como resistência: Teresa 17
}

[ Coherence as resistance: "Teresa" I7

\section{Nicola Gavioli ${ }^{\mathbf{1}}$}

GINZBURG, Jaime (Org.). Teresa - revista de literatura brasileira n. I7 (dossiê Autoritarismo e Violência). Editores responsáveis: Jaime Ginzburg e Marcos Flamínio Peres. Programa de Pós-Graduação em Literatura Brasileira. São Paulo: Departamento de Letras Clássicas e Vernáculas. Faculdade de Filosofia, Letras e Ciências Humanas. Universidade de São Paulo, 2016.

"Autoritarismo" e "violência" são núcleos temáticos fortes da pesquisa de Jaime

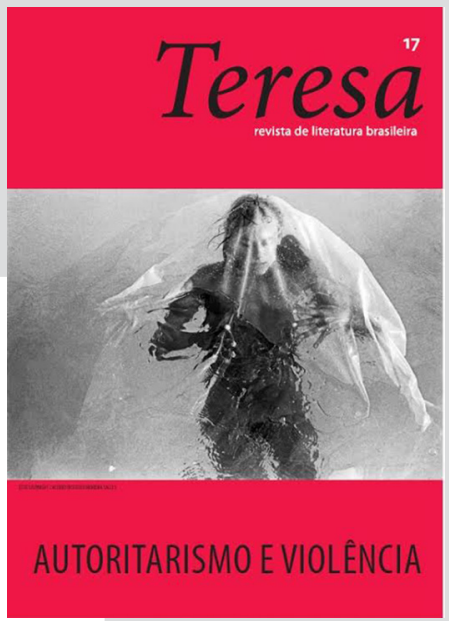
Ginzburg, responsável pelo número I7 da revista Teresa - revista de literatura brasileira. Ginzburg é autor de ensaios acadêmicos, livros (Crítica em tempos de violência, Edusp/Fapesp, 20I2; Literatura, violência e melancolia, Autores Associados, 2013), coorganizador dos volumes Escritas da violência I e II (em colaboração com Márcio Seligmann-Silva e Francisco Foot Hardman, 7 Letras, 20I2), Walter Benjamin: rastro, aura e história (com Sabrina Sedmayer, UFMG, 20I2) e de dossiês da revista Literatura e autoritarismo (Universidade Federal de Santa Maria - UFSM). A coerência não é apenas detectável na organização dos materiais que compõem esse número de Teresa, mas caracteriza o percurso acadêmico de Ginzburg no seu conjunto. A revista é a contribuição mais recente de um pesquisador que se ocupa criticamente de representações da violência na literatura brasileira há muitos anos.

GAVIOLI, Nicola. Coerência como resistência: Teresa I7. Revista do Instituto de Estudos Brasileiros, Brasil, n. 67, p. 234-238, ago. 2017.

DOI: http://dx.doi.org/Io.II6o6/issn.23I6-90IX.voi67p234-238

I Florida International University (FIU, Miami, Flórida, EUA). 
Nas seções que constituem Teresa I7 - Artigos, Documentos, Entrevistas, Resenhas, Contribuições - se detectam ecos e preocupações comuns. O organizador privilegiou a coesão entre todas as partes da revista, evitando coletar uma miscelânea de textos só parcialmente pertinentes ao tema escolhido. As três fotografias em preto e branco de Otto Stupakoff (Acervo Instituto Moreira Salles), inseridas nas primeiras páginas, oferecem um inquietante portal de acesso aos ensaios. $O$ corpo de uma jovem mulher, bela e parcialmente despida, contida como uma crisálida num enorme saco de plástico deitado numa substância líquida (os dedos de suas mãos tentando resistir ao material que a encapsula); um menino com a cabeça encostada na parede à procura de uma passagem impossível (que deve ser rabiscada para ela poder existir); o mesmo menino, dessa vez numa postura de castigo, com a cabeça novamente rebaixada, e novos rabiscos na parede. Solidão, claustrofobia, castigo, e vulnerabilidade.

A apresentação de Jaime Ginzburg explicita as razões dessa publicação, seu conteúdo, a influência crítica (Walter Benjamin) e a vontade de despertar debates. Contra "a apatia acadêmica" e contra "o fascismo em todas as suas faces" (p. 9-Io), Teresa I7 é um projeto que inclui nomes consagrados da ensaística brasileira e pesquisadores mais jovens (como a norte-americana Sophia Beal). A revista demonstra como um trabalho acadêmico sério é constituído por algumas características imutáveis: o foco num tema específico, o rigor nas argumentações e a tentativa de comunicar a complexidade aos leitores.

A divisão em seções segue a organização tradicional da revista Teresa, com uma novidade importante: o espaço dedicado às entrevistas-ensaios é, em relação aos números anteriores, considerável (com exceção dos números Io e II, nos quais havia entrevistas com escritores contemporâneos, mas que não tinham a mesma densidade teórica desse número I7).

Algumas informações gerais sobre a seção Artigos:

a) privilegia-se o gênero romance, com exceção de dois contos de Caio Fernando Abreu e de recentes obras de não fiç̧ão;

b) o Brasil é o contexto principal em todos os artigos, mas há referências a outras 
situações de violência (em particular, na Argentina e nos Estados Unidos);

c) a ordem dos artigos segue afinidades temáticas: a "violência de estado" e os aspectos psicológicos do terror, em Joachim Michael e Marcus Rogério Salgado; o contexto urbano e a violência, em Leila Lehnen e Sophia Beal; a tortura, em Táscia Souza e Jovita Noronha e em Rosani Umbach;

d) o artigo final dessa seção (de Vitor Blotta) se destaca por ser o único texto em inglês da revista, pela abertura a gêneros não tradicionais, como o romance gráfico e a reportagem, mas sobretudo por enfrentar o tema controverso do "monopólio do lugar de fala” na narrativa do trauma;

e) perpassa os vários textos a ideia da literatura como o espaço de antagonismo e de resistência contra a retórica de discursos políticos e mediáticos mais conservadores e autoritários. Fake news e aspirações autoritárias se deram as mãos no passado (aconselha-se visitar o museu da ex-Esma - Escola de Mecânica da Armada argentina, cuja sede foi um centro clandestino de detenção e tortura durante a ditadura militar eque hoje abriga o Espaço Memória e Direitos Humanos, em Buenos Aires: numa de suas salas se encontra a impressionante amostra de jornais e revistas importantes que se renderam à ditadura); hoje a difusão da informação on-line adiciona mais um elemento de possível manipulação das notícias a serviço de poderes autoritários.

O ensaio de Joachim Michael, "Memória do desaparecimento: a ditadura no romance K. Relato de uma busca, de Bernardo Kucinski”, problematiza a passagem do ensaio ao romance por parte de Kucinski, evidenciando a capacidade que a literatura tem para representar os efeitos emotivos e sociais do trauma, denunciar as técnicas perversas do poder, e ao mesmo tempo questionar seus próprios limites e incapacidades ("o romance deixa transparecer uma visão cética da literatura” - p. 28). O romance $K$., de Kucinski, é considerado uma referência da literatura sobre desaparecidos na América Latina, e foi já objeto de numerosos ensaios. $\mathrm{O}$ belo ensaio de Joachim Michael teria se beneficiado ao estabelecer um diálogo com outros estudos publicados sobre esse romance.

Marcos Rogério Salgado dedica seu texto "O tirano e o látego: um estudo sobre a violência de Estado em dois romances de Dyonélio Machado” a uma produção menos conhecida do autor rio-grandense-do-sul. Como no ensaio de Michael, Salgado considera os aspectos psicológicos do terror. Um elemento de destaque desse ensaio é a reflexão sobre a paranoia como instrumento de repressão.

Os ensaios de Leila Lehnen ("Cartografias da cidadania diferenciada em Luiz Ruffato e Guillermo Saccomanno”) e de Sophia Beal (“Espaços movediços e conflitantes na Manaus de Milton Hatoum”) colocam perguntas sobre cidadania, marginalidade e desigualdade social presentes nas grandes cidades da América Latina. A nova narrativa latino-americana (Ruffato, Saccomanno, Hatoum) mostra sua sensibilidade em relação a temas de "política do espaço" (Lehnen, p. 54) e seu engajamento contra imaginários esquemáticos e banais sobre as cidades. 
Em "A coroa de Cristo x O beijo de Judas: Batismo de sangue e a denúncia da violência”, Táscia Oliveira Souza e Jovita Maria Gerheim Noronha defendem a capacidade da narrativa (nesse caso, de um texto híbrido entre o literário e o memorialístico) para denunciar e desconstruir memórias falsas e ignominiosas preservadas na história por um jornalismo manipulador. A tortura é aqui tratada, como no ensaio de Rosani Úrsula Ketzer Umbach ("Tortura e violência de Estado em dois contos de Caio Fernando Abreu”), como um dos crimes mais destrutivos para a personalidade. Rancière e Arendt oferecem a Umbach o aparato teórico para pensar a tortura em textos de Abreu.

O último ensaio da seção Artigos é "'You will never understand': the monopoly of the place of speech through cultural trauma narratives in Brazil", de Vitor Blotta. Nele, o autor problematiza o "monopólio" - termo infeliz para indicar a "autoridade" atribuída a certas vítimas - do lugar de fala do trauma. O texto oferece instigantes perspectivas sobre a possível crítica desse "monopólio" através da análise de reportagens e romances gráficos brasileiros. Talvez uma análise mais aprofundada dos recursos verbais e gráficos neles adotados (e um corpus bibliográfico mais reduzido) teria beneficiado esse texto teoricamente exigente.

A seção Documentos enriquece a revista com introduções e análises de textos de Gonçalves Dias, Álvares de Azevedo, Castro Alves, Pedro Luís, Gregório de Matos, Manuel Antônio de Almeida, Taunay e Machado de Assis. Os textos estão todos relacionados com a violência: revolução, mau governo, guerra, opressão colonial, e até violência sádica doméstica (em Machado).

A terceira seção é constituída pelas entrevistas de Jaime Ginzburg com nomes fundamentais da crítica brasileira. Trata-se de longas entrevistas (não entrevistas jornalísticas, mas densas entrevistas-ensaios), que têm como ponto de partida um livro ou artigos dos entrevistados. As perguntas são teóricas, complexas, pressupõem uma elaboração crítica por escrito (pode-se apreciar também as diferenças estilísticas e pessoais de cada entrevistado). Existe também uma preocupação "concreta", didática e metodológica: "Poderias dar exemplos, de acordo com suas pesquisas, em que a ideologia patriarcal teria contribuído para a falta de reconhecimento de obras literárias importantes?” (entrevista com Rita Terezinha Schmidt, p. 26I), "Especificamente, em caso de textos literários que abordam a violência, como conhecimentos de psicanálise poderiam beneficiar a qualidade de reflexões acadêmicas sobre esses textos?” (entrevista com Christian Ingo Lenz Dunker, p. 3I2).

A seção de entrevistas começa com as reflexões mais teóricas de Francisco Foot Hardman e Roberto Vecchi. Seguem - em síntese - considerações sobre literatura colonial (João Adolfo Hansen), historiografia literária, cânones e pedagogia (Rita Terezinha Schmidt), realismo contemporâneo (Karl Erik Schollhammer), poesia, violência, literatura "marginal" e testemunho (João Camillo Penna), Machado, João Guimarães Rosa e o papel dos intelectuais hoje (Luiz Roncari), Érico Veríssimo (Maria da Glória Bordini), literatura e psicanálise (Christian Dunker). Todos os entrevistados mostram preocupação com o estado presente do país. Rita Terezinha Schmidt afirma, por exemplo, que nos ambientes intelectuais brasileiros se assiste a um "recrudescimento" do conservadorismo "apesar de tantos avanços no campo da teoria” (p. 257). Francisco Foot Hardman denuncia a “onda reacionária” na política do 
país (p. 230). O conjunto dessas entrevistas leva o leitor a pensar o que a literatura e o ensino da literatura podem fazer para nomear e enfrentar os aspectos conservadores e autoritários circulantes nos discursos políticos, mediáticos e pedagógicos do ano 2017.

Na parte conclusiva da revista, três resenhas pertinentes ao tema da violência, uma entrevista com o pesquisador italiano Ettore Finazzi-Agrò por Antonio Dimas, e uma resenha sobre uma coletânea de poesia erótica brasileira.

Teresa I7 não é obra de divulgação, mas de aprofundamento e questionamento. Embora o formato on-line favoreça a sua difusão, o número mereceria ser impresso e colocado nas bibliotecas universitárias, junto a obras de referência sobre violência e literatura.

\section{SOBRE O AUTOR}

NICOLA GAVIOLI é professor de Literatura Brasileira na Florida International University de Miami. Organizou, com Vinicius Mariano de Carvalho (King's College, Londres), o volume de ensaios Literature and ethics in contemporary Brazil (Routledge, 20I7).

E-mail:ngavioli@fiu.edu 